\title{
Reductive Intramolecular Cyclization of D-Glucose-Based Unsaturated Substrates by Indirect Electrochemical Approach in "Green" Media
}

\author{
T.A. Dias ${ }^{\mathrm{a}}$, C. Durães ${ }^{\mathrm{a}}$, A.P. Esteves ${ }^{\mathrm{a}}$, M.J. Medeiros ${ }^{\mathrm{a}, *}$ and D. Pletcher ${ }^{\mathrm{b}}$ \\ ${ }^{a}$ Centro de Química, Universidade do Minho, Largo do Paço, 4704-553 Braga, Portugal \\ ${ }^{b}$ Department of Chemistry, University of Southampton, SO 171 BJ Southampton, U.K.
}

Radical cyclisation continues to be a central methodology for the preparation of natural products containing heterocyclic rings. Hence, some electrochemical results obtained by cyclic voltammetry and controlled-potential electrolysis in the study of electroreductive intramolecular cyclisation of ethyl $(2 \mathrm{~S}, 3 \mathrm{R})-2$ bromo-3-propargyloxy-3-(2',3',4',6'-tetra-O-acetyl- $\beta$-D-glucopyranosiloxy) propanoate (1) promoted by (1,4,8,11-tetramethyl1,4,8,11-tetraazacyclotetra-decane)nickel(I), $\quad[\mathrm{Ni}(\mathrm{tmc})]^{+}$, electrogenerated at glassy carbon cathodes in ethanol and ethanol/water mixtures containing tetraalkylammonium salts, are presented.

During controlled-potential electrolyses of solutions containing $[\mathrm{Ni}(\mathrm{tmc})]^{2+}$ and acetylated D-glucose-based bromo propargyl ester (1) catalytic reduction of the latter proceeds via one-electron cleavage of the carbon-bromine bond to form a radical intermediate that undergoes cyclization to afford the substituted tetrahydrofurans.

\section{Introduction}

Owing to their widespread presence in nature as well as their breadth of biological activity, lignans have attracted considerable attention from organic chemists (1). Some lignans exhibit anti-tumor activity, whereas others function as diuretic, analgesic, and anti-rheumatic compounds (2). A major subgroup of lignans is comprised by tri- and tetra-substituted tetrahydrofurans, which are very useful precursors for the synthesis of a variety of natural products with biological activity (2).

Although several synthetic approaches have been reported, radical cyclization continues to be a central methodology for the preparation of natural products containing heterocyclic rings (3). A majority of radical cyclizations in heterocyclic chemistry are still accomplished with the aid of tri- $n$-butyltin hydride, $\mathrm{Bu}_{3} \mathrm{SnH}$, as a stoichiometric reagent (3).

To avoid the use of toxic triorganotin hydrides, which are also troublesome to separate from the desired products, considerable effort has been aimed at development of more ecofriendly methodologies for the generation of reactive radicals. The electrochemical nickel-catalyzed radical-type cyclisations has been shown to be a convenient alternative for the synthesis of heterocyclic compounds (4).

Our research group has some experience in the catalytic reductive cyclization of unsaturated halides to produce substituted tri- and tetrahydrofurans, by indirect electroreduction using $\mathrm{Ni}(\mathrm{II})$ complexes as the catalysts (5). 
In order to develop an environmentally friendly method for radical cyclisation of Dglucose-based unsaturated substrates, we have investigated this reaction by indirect electrochemical methods using $\mathrm{Ni}$ (II) macrocyclic complexes as catalysts in ethanol and ethanol/water mixtures under several experimental conditions using cyclic voltammetry and controlled-potential electrolysis.

\section{Results and Discussion}

The Electrochemistry of ethyl (2S, 3R)-2-bromo-3-propargyloxy-3-(2',3',4',6'-tetra-Oacetyl- $\beta$-D-glucopyranosiloxy) propanoate $(\underline{\mathbf{1}})$

Cyclic voltammograms were obtained at different scan rates at a vitreous carbon electrode for $1 \mathrm{mM}$ solutions of acetylated D-glucose-based bromo propargyl ester $\underline{\mathbf{1}}$ in EtOH containing $0.10 \mathrm{M}$ TEABr. Figure 1, curve A, shows a cyclic voltammogram obtained at $0.10 \mathrm{~V} \mathrm{~s}^{-1}$ at a vitreous carbon electrode; only a single, highly irreversible reduction wave is seen at potentials near to $-1.50 \mathrm{~V}$ vs an aqueous $\mathrm{Ag} / \mathrm{AgCl} / 3 \mathrm{M} \mathrm{KCl}$. This peak probably corresponds to the reductive cleavage of the carbon-bromine bond. Similar results were obtained in cyclic voltammetric studies carried out in EtOH: $\mathrm{H}_{2} \mathrm{O}$ containing 0.10 M TEABr.

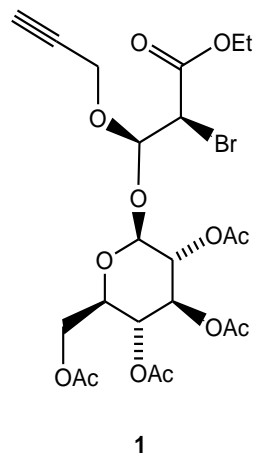

The Reduction of the $[\mathrm{Ni}(\mathrm{tmc})] \mathrm{Br}_{2}$ Complex

A cyclic voltammetric study of solutions of $[\mathrm{Ni}(\mathrm{tmc})] \mathrm{Br}_{2}$ complex was carried out in $\mathrm{EtOH}$ and in EtOH-H $\mathrm{H}_{2} \mathrm{O}(9: 1)$ containing $0.10 \mathrm{M}$ TEABr. Hence, cyclic voltammograms were recorded at a series of potential scan rates between 0.020 and 0.200 $\mathrm{V} \mathrm{s}^{-1}$ at a vitreous carbon electrode for solutions of $[\mathrm{Ni}(\mathrm{tmc})] \mathrm{Br}_{2}$ complex in EtOH / $\operatorname{TEABr}(0.1 \mathrm{M})$ and in Figure 1, curve B, can be seen a cyclic voltammogram recorded at $0.10 \mathrm{~V} \mathrm{~s}^{-1}$. The figure shows that the complex underwent a reversible one-electron reduction to a stable product and that no further reduction occurred within the potential range of the medium. Similar results have been obtained in cyclic voltammetric studies carried out in EtOH- $\mathrm{H}_{2} \mathrm{O}$ containing $0.1 \mathrm{M}$ TEABr. Formal electrode potentials are $0.86 \mathrm{~V}$ ws $\mathrm{Ag} / \mathrm{AgCl} / 3 \mathrm{M} \mathrm{KCl}$ and $-0.87 \mathrm{~V}$ ws $\mathrm{Ag} / \mathrm{AgCl} / 3 \mathrm{M} \mathrm{KCl}$ in EtOH / TEABr $(0.1$ M) and $\mathrm{EtOH}: \mathrm{H}_{2} \mathrm{O} / \mathrm{TEABr}(0.1 \mathrm{M})$, respectively. 
The Electrochemistry of the $[\mathrm{Ni}(\mathrm{tmc})] \mathrm{Br}_{2}$ Complex in the Presence of Acetylated DGlucose-Based Bromo Propargyl Ester 1

Figure 1 also shows two cyclic voltammograms recorded for solutions of $[\mathrm{Ni}(\mathrm{tmc})] \mathrm{Br}_{2}$ in the presence of different concentrations of acetylated D-glucose-based bromo propargyl ester $\underline{1}$ in EtOH / TEABr $(0.1 \mathrm{M})$. The experiments show that addition of D-glucose-based bromo propargyl ester $\underline{1}$ to the [ $\mathrm{Ni}(\mathrm{tmc})] \mathrm{Br}_{2}$ complex solution results in the increase of the reduction peak height of the mediator and disappearance of the anodic wave (Figure 1, curve C). On further addition of $\underline{\mathbf{1}}$, the cathodic current increased further (Figure 1, curve D). Furthermore, with progressive increases in the concentration of $\underline{\mathbf{1}}$, the cathodic peak potential shifted toward more negative values.

Similar behaviour was observed when these experiments were performed in EtOH: $\mathrm{H}_{2} \mathrm{O}$ (9:1) / TEABr $(0.1 \mathrm{M})$. The catalytic current is due to the following mechanism:

$$
\begin{aligned}
& {[\mathrm{Ni}(\mathrm{tmc})]^{2+}+\mathrm{e}^{-} \rightleftharpoons[\mathrm{Ni}(\mathrm{tmc})]^{+}} \\
& {[\mathrm{Ni}(\mathrm{tmc})]^{+}+\mathrm{RBr} \longrightarrow[\mathrm{Ni}(\mathrm{tmc})]^{2+}+\text { products }}
\end{aligned}
$$

The data from these experiments are presented in Table 1.

From these data we can observe that the extent of the catalytic reaction increases when raising $[\mathrm{RBr}]$, for a given mediator concentration.

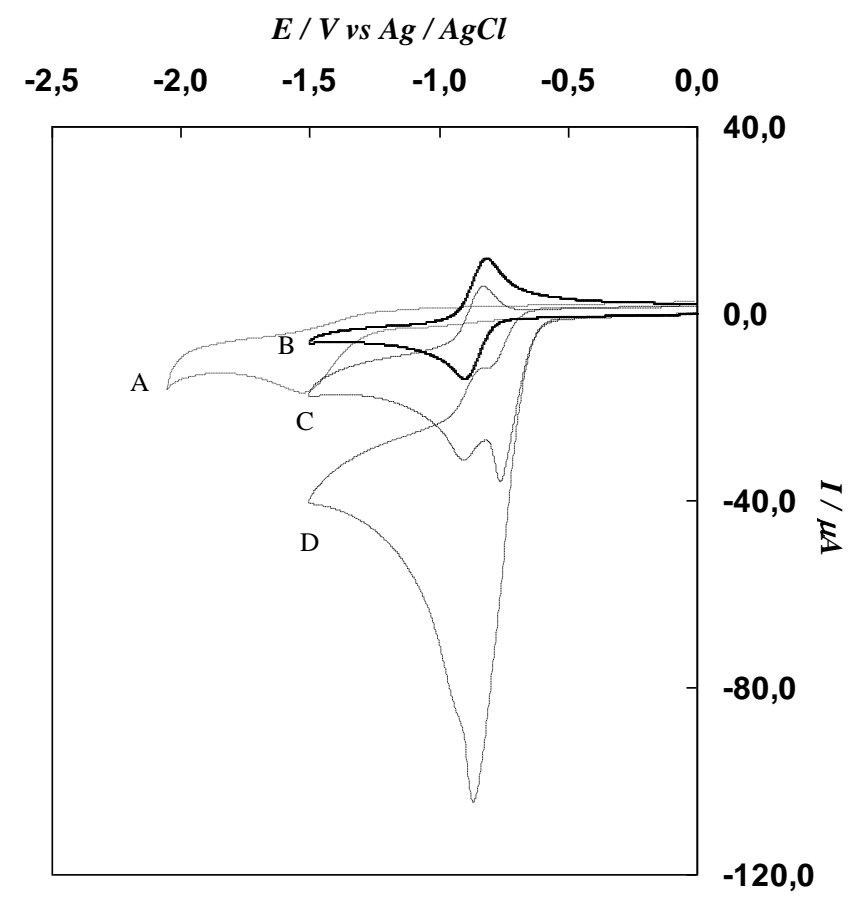

Figure 1 - Cyclic voltammograms recorded at a vitreous carbon electrode (area, $0.070 \mathrm{~cm}^{2}$ ) at a scan rate of $0.10 \mathrm{Vs}^{-1}$ in EtOH containing $0.10 \mathrm{M} \mathrm{TEABr}:$ (A) $1.0 \mathrm{mM} \underline{\mathbf{1}}$; (B) $1.0 \mathrm{mM}\left[\mathrm{Ni}\left(\mathrm{tmc}^{\mathrm{m}}\right)\right] \mathrm{Br}_{2}$; (C) $1.0 \mathrm{mM}$ $[\mathrm{Ni}(\mathrm{tmc})] \mathrm{Br}_{2}$ and $2.0 \mathrm{mM} \underline{\mathbf{1}}$; (D) $1.0 \mathrm{mM}[\mathrm{Ni}(\mathrm{tmc})] \mathrm{Br}_{2}$ and $10.0 \mathrm{mM} \underline{\mathbf{1}}$. 
Table 1 - Data of the ratio $I_{c} / I_{d}$ obtained from the cyclic voltammetry experiments of $1.0 \mathrm{mM}[\mathrm{Ni}(\mathrm{tmc})] \mathrm{Br}_{2}$ complex in the presence of different concentrations of $\underline{1}$ in aqueous media. Potential scan rate $0.10 \mathrm{~V} / \mathrm{s}$.

\begin{tabular}{lcccc}
\hline \multirow{2}{*}{ Medium } & \multicolumn{3}{c}{$\mathbf{I}_{\mathbf{c}} / \mathbf{I}_{\mathbf{d}}{ }^{\mathbf{a}}$} \\
\cline { 2 - 5 } $\mathrm{EtOH} / 0.10 \mathrm{M} \mathrm{TEABr}$ & $\gamma=1^{\mathrm{b}}$ & $\gamma=2^{\mathrm{b}}$ & $\gamma=7^{\mathrm{b}}$ & $\gamma=10^{\mathrm{b}}$ \\
\cline { 2 - 5 } & 0.9 & 2.5 & 5.6 & 9.2 \\
\cline { 2 - 5 } $\mathrm{EtOH}: \mathrm{H}_{2} \mathrm{O}(9: 1) / / 0.10 \mathrm{M} \mathrm{TEABr}$ & $\gamma=1^{\mathrm{b}}$ & $\gamma=2^{\mathrm{b}}$ & $\gamma=6^{\mathrm{b}}$ & $\gamma=10^{\mathrm{b}}$ \\
\hline
\end{tabular}

${ }^{\text {a }}$ Ic - catalytic peak current intensity of the catalyst in the presence of substrate and Id - peak current intensity of the catalyst in the absence of substrate; ${ }^{b} \gamma=[\mathrm{RBr}] /[\mathrm{Ni}$ (II)].

Controlled-potential Electrolyses of $[\mathrm{Ni}(\mathrm{tmc})] \mathrm{Br}_{2}$ Complex in the Presence of Acetylated D-Glucose-Based Bromo Propargyl Ester 1

Controlled-potential electrolyses of solutions of $[\mathrm{Ni}(\mathrm{tmc})] \mathrm{Br}_{2}$ in the presence of acetylated D-glucose-based bromo propargyl ester $\underline{1}$ in EtOH and in EtOH: $\mathrm{H}_{2} \mathrm{O}$ (9:1) containing $0.10 \mathrm{M}$ TEABr at reticulated vitreous carbon cathode were performed. The potential was set at approximately $100 \mathrm{mV}$ negative to the peak potential of the reduction wave of the catalyst in the presence of the unsaturated halide $\underline{1}$. The data from those experiments are presented in Table 2.

Three general conclusions can be drawn from the results presented in Table 2. First, an $n$ value of essentially 1.3 was observed for the catalytic reduction of $\underline{\mathbf{1}}$ but in the presence of 1,1,1,3,3,3-hexafluoro-2-propanol (HFIP) acting as a proton donor an $n$ value of 1 was found. Second, ${ }^{1} \mathrm{H}$ NMR analysis of the electrolyzed mixtures reveals the presence of two major products, ethyl 4-methylfuran-3-carboxylate $(\underline{\mathbf{3}})$ and tetraacetylglucose $(\underline{4})$. Third, the compound $\underline{\mathbf{2}}$ was only formed in the presence of a proton donor and the yield seems to depend on the concentration of HFIP (Table 2, entries 4,5,6).<smiles>[R]OC1OCC(=C)C1COCC</smiles>

$\underline{2}$<smiles></smiles>
OAc OAc<smiles>CCOC(=O)c1cocc1C</smiles>

$\underline{3}$<smiles>CC(=O)OCC1OC(O)[C@H](OC(C)=O)[C@H](OC(C)=O)[C@H]1OC(C)=O</smiles>

4 
Table 2 . Coulometric Data and Product Distributions for Catalytic Reduction of 1 by $[\mathrm{Ni}(\mathrm{tmc})]^{+}$Electrogenerated at Reticulated Vitreous Cathodes in EtOH Containing 0.10 M TEABr

\begin{tabular}{|c|c|c|c|c|c|c|c|}
\hline \multirow[b]{2}{*}{ entry } & \multirow[b]{2}{*}{ Solvent } & \multirow[b]{2}{*}{$\frac{[\mathrm{Ni}(\mathrm{tmc})]^{2+},}{\mathrm{mM}}$} & \multirow[b]{2}{*}{$\begin{array}{l}{[\underline{1}],} \\
\mathrm{mM}\end{array}$} & \multirow[b]{2}{*}{$\begin{array}{c}{[\mathrm{HFIP}]} \\
\mathrm{mM}^{b}\end{array}$} & \multirow[b]{2}{*}{$n^{c}$} & \multicolumn{2}{|c|}{$\begin{array}{c}\text { product } \\
\text { distribution, } \%^{a}\end{array}$} \\
\hline & & & & & & $\underline{2}$ & $\frac{\underline{3}+\underline{4}}{\text { (ratio) }}$ \\
\hline 1 & $\begin{array}{c}\text { EtOH: } \mathrm{H}_{2} \mathrm{O} \\
(9: 1)\end{array}$ & 0.94 & 1.9 & - & 1.5 & - & $\begin{array}{c}100 \\
(43: 57)\end{array}$ \\
\hline 2 & $\mathrm{EtOH}$ & 0.94 & 5.0 & - & 1.2 & - & $\begin{array}{c}71 \\
(50: 50)\end{array}$ \\
\hline 3 & $\mathrm{EtOH}$ & 0.94 & 5.0 & 9 & 1.0 & - & $\begin{array}{c}100 \\
(40: 60)\end{array}$ \\
\hline 4 & $\mathrm{EtOH}$ & 0.94 & 5.0 & 19 & 1.0 & 100 & - \\
\hline 5 & $\mathrm{EtOH}$ & 0.94 & 5.0 & 28 & 1.0 & 100 & - \\
\hline 6 & $\mathrm{EtOH}$ & 0.94 & 5.0 & 47 & 1.0 & 52 & $\begin{array}{c}19 \\
(5: 95)\end{array}$ \\
\hline
\end{tabular}

${ }^{a} \%=$ yield expressed as the percentage of $\underline{\mathbf{1}}$ incorporated into each product. ${ }^{b} \mathrm{HFIP}=1,1,1,3,3,3$-hexafluoro2-propanol. ${ }^{c}$ Number of electrons per molecule of starting material.

In conclusion: (i) The experimental results presented suggest that the catalytic electroreductive cyclization of the bromoester $\underline{\mathbf{1}}$ catalized by $[\mathrm{Ni}(\mathrm{tmc})] \mathrm{Br}_{2}$ complex in EtOH afford the cyclic compound in yields good enough to make this procedure an alternative to other synthetic methods; (ii) An advantage of this method is that the radical reactions can be carried out using a catalytic amount of a complex of an appropriate metal, at room temperature, in an environmentally friendly medium.

\section{Acknowledgments}

We are grateful to the Fundação para a Ciência e Tecnologia for financial support of this work (PPCDT/QUI/55576/2004).

\section{References}

1. (a) Chemistry of Lignans, Ed. C.B.S. Rao, Andhra University Press (1978). (b) D.A. Whiting, Natural Products Reports, 191 (1985); 499 (1987); 349 (1990).

2. O.R. Gottlieb in New Natural Products and Plant Drugs with Pharmacological, Biological or Therapeutical Activity, p. 227-248, Springer-Verlag, Berlin-Heidelberg (1987).

3. (a) B. Giese, Radicals in Organic Synthesis: Formation of Carbon-Carbon Bonds, Pergamon Press, Oxford (1986); (b) A.L.J. Beckwith, Chem. Soc. Rev. 143 (1993); (c ) B. 
Giese, B. Kopping, T. Gobel, J. Dickhaut, G. Thoma, F. Trach., Org. React. 48, 301 (1996) (and references therein).

4. (a) S. Ozaki, E. Matsui, J. Waku, H. Ohmori, Tetrahedron Lett., 38, 2705 (1997) (and references cited therein); (b) S. Olivero, J. -P. Rolland, E. Duñach, Organometallics, 17, 3747 (1998) (and references cited therein).

5. (a) A.P. Esteves, D.M. Goken, L.J. Klein, M.J. Medeiros, D.G. Peters, Eur. J. Org. Chem., 4852 (2005) (and references cited therein); (b) A.P. Esteves, E.C. Ferreira, M. J. Medeiros, Tetrahedron, 63, 3006 (2007) (and references cited therein); (c) E. Duñach, A. P. Esteves, M. J. Medeiros, S. Olivero, Green Chemistry, 8, 380 (2006). 